\title{
Analysis of Oxidative Stress Enzymes and Structural and Functional Proteins on Human Aortic Tissue from Different Aortopathies
}

\author{
María Elena Soto, ${ }^{1}$ Elizabeth Soria-Castro, ${ }^{2}$ Verónica Guarner Lans, ${ }^{3}$ \\ Eleazar Muruato Ontiveros, ${ }^{4}$ Benjamín Iván Hernández Mejía, ${ }^{4}$ \\ Humberto Jorge Martínez Hernandez, ${ }^{4}$ Rodolfo Barragán García, \\ Valentín Herrera, ${ }^{4}$ and Israel Pérez-Torres ${ }^{2}$ \\ ${ }^{1}$ Immunology Department, National Institute of Cardiology "Ignacio Chavez", Juan Badiano 1, Sección XVI, Tlalpan, \\ 14080 Mexico City, DF, Mexico \\ ${ }^{2}$ Pathology Department, National Institute of Cardiology "Ignacio Chavez", Juan Badiano 1, Sección XVI, Tlalpan, \\ 14080 Mexico City, DF, Mexico \\ ${ }^{3}$ Physiology Department, National Institute of Cardiology "Ignacio Chavez", Juan Badiano 1, Sección XVI, Tlalpan, \\ 14080 Mexico City, DF, Mexico \\ ${ }^{4}$ Cardiovascular Surgery Department, National Institute of Cardiology "Ignacio Chavez", Juan Badiano 1, Sección XVI, Tlalpan, \\ 14080 Mexico City, DF, Mexico
}

Correspondence should be addressed to Israel Pérez-Torres; pertorisr@yahoo.com.mx

Received 4 April 2014; Revised 28 May 2014; Accepted 28 May 2014; Published 1 July 2014

Academic Editor: Kota V. Ramana

Copyright ( 2014 María Elena Soto et al. This is an open access article distributed under the Creative Commons Attribution License, which permits unrestricted use, distribution, and reproduction in any medium, provided the original work is properly cited.

\begin{abstract}
The role of oxidative stress in different aortopathies is evaluated. Thirty-two tissue samples from 18 men and 14 women were divided into: 4 control (C) subjects, 11 patients with systemic arterial hypertension (SAH), 4 with variants of Marfan's syndrome (MV), 9 with Marfan's syndrome (M), 2 with Turner's syndrome, and 2 with Takayasu's arteritis (TA). Aorta fragments were homogenized. Lipoperoxidation (LPO), copper-zinc and manganese superoxide dismutase ( $\mathrm{Mn}$ and $\mathrm{Cu}-\mathrm{Zn}$-SOD), catalase (CAT), glutathione peroxidase (GPx), glutathione S-transferase (GST), endothelial nitric oxide synthase (eNOS), nitrates and nitrites $\left(\mathrm{NO}_{3}{ }^{-} / \mathrm{NO}_{2}{ }^{-}\right.$), and type IV collagen, and laminin were evaluated. There was an increase in $\mathrm{Mn}$ - and $\mathrm{Cu}-\mathrm{Zn}$-SOD activity in SAH, MV, M, and Turner's syndrome. There was also an increase in CAT activity in M and Turner' syndrome. GPx and GST activity decreased and LPO increased in all groups. eNOS was decreased in $\mathrm{SAH}, \mathrm{MV}$, and $\mathrm{M}$ and $\mathrm{NO}_{3}{ }^{-} / \mathrm{NO}_{2}{ }^{-}$were increased in SAH and TA. Type IV collagen was decreased in Turner's syndrome and TA. Laminin $\gamma-1$ was decreased in MV and increased in M. In conclusion, similarities and differences in oxidative stress in the different aortopathies studied including pathologies with aneurysms were found with alterations in SOD, CAT, GPx, GST, and eNOS activity that modify subendothelial basement membrane proteins.
\end{abstract}

\section{Introduction}

Oxidative stress is caused by an imbalance between the production of reactive oxygen species (ROS) and the antioxidant capacity of the biological system. It requires rapid detoxification of intermediate reactants or the repair of the damage and it alters the essential processes possibly becoming the origin of tissue damage in the organism [1-3].
Aortic pathologies, characterized by the loss of contractile function and endothelium-mediated relaxation, are related to oxidative stress and vascular dysfunction [4-6]. Besides, the mechanical properties of the vessel transform [7], leading to pseudoaneurysm or aneurysm formation, to obstruction or destruction of the vessel $[8,9]$. Even though the origin of aortic damage might be multifactorial, molecular oxygen could play a critical role in vascular tonicity, cardiac contractility, 
and other parameters. Molecular oxygen participates in ROS genesis and/or can induce irreversible damage and even death. However, it can also have beneficial effects, participating in cellular signaling processes [10]. Oxidative stress has been involved in cardiovascular diseases $[2,11,12]$, such as arrhythmias, coronary arterial disease, left ventricular hypertrophy, aortic dilatation, aortic dissection, and congestive heart failure. ROS and reactive nitrogen species (RNS) are produced in these diseases through different pathways such as mitochondrial xanthine oxidase and NADPH oxidase (Nox). Endothelial nitric oxide synthase (eNOS) also plays a relevant role in them [13-24].

Structural and functional damage is present in the aortic walls in different human diseases such as hypertension (SAH), atherosclerosis, Takayasu's arteritis (TA), Turner's syndrome, and Marfan's syndrome (M) and its variants (MV) [25-28]. In them, aortic damage, stenosis, occlusion, aneurysms or pseudoaneurysms [29-31], and endothelial dysfunction [32-34] have been described. These findings have been described independently for each disease having a specific genetic background, appearing at different ages and in subjects of different genders and exposed to different environments such as infections or trauma. However, they all require similar surgical treatment [35].

The role of oxidative stress in aortic damage progression in some pathologies has already been described [7, 36]; however, in others, human tissues are scarce $[37,38]$. Therefore, a study of oxidative stress and antioxidants in the aorta from patients with aortic damage is justified.

The aim of this paper is to evaluate the role of oxidative stress in human aortas from patients with different pathologies where aortic damage is present. Tissue was obtained by elective surgery or emergency. We also evaluate subendothelial basement membrane proteins.

\section{Materials and Methods}

2.1. Patients. 18 men and 14 women treated at our institution and who met a surgical criteria for either elective or emergency surgery by Bentall and Bono's method [39] were included in a consecutive way as soon as aortic root dilatation (>50 mm) was demonstrated by computed tomography angiography.

The samples collected were taken from patients with M, classified by the Ghent's criterion in 1996 [40], and TA diagnosed by the standards of the American College of Rheumatology (ACR) [41] and patients with hypertension (SAH) and Turner's syndrome [42]. Once patients fulfilled the inclusion criteria they went through a thorough clinical examination to determine the extent of their cardiac pathology. The results were analyzed and presented in a clinic and pathological conference where cardiovascular specialists assessed the risks and benefits of a surgical intervention. The subjects were submitted to a preoperative protocol that included coagulation tests, X-rays, electrocardiogram, anesthesia evaluation, and individualized medical intervention. Cases were dealt with caution, to avoid including patient undertaking treatments with antioxidants, allopurinol, or probable inhibitors of pathways involved in ROS production. Aspirin, warfarin, clopidogrel, and other antiplatelet or anticoagulant medications were suspended. Control tissues were obtained from patients who underwent surgery for aortic stenosis, who had no syndromic pathology diagnosed, and in whom there was no suspicion of inflammatory diseases such as TA or atherosclerosis nor presence of degenerative disorders such as diabetes mellitus, arterial hypertension, thyroid, or autoimmune diseases. The surgery performed implied substitution of aortic valves and there was a need to perform plasty or resection of aortic tissue surrounding the valvular area. Control subjects were evaluated previously to surgery by an expert cardiologist and rheumatologist to verify that none of the above mentioned diseases was present and routine laboratory tests were made to determine acute phase reactants, triglycerides, and HDL cholesterol. Additionally to image studies by echocardiography, computerized tomography or magnetic resonance studies were done to discard aortic damage additional to valvular damage. None of the control subjects was taking anti-inflammatory drugs or statins. The research protocol was approved by the Research and Ethics Committee of our institution (Institutional protocol number: 09654). Informed consent of patients and controls was obtained for the anesthetic procedure and surgery and to obtain a tissue sample, according to the Declaration of Helsinki [43]. Once the surgery was performed, the tissue was placed in liquid nitrogen and was kept at $-70^{\circ} \mathrm{C}$ until use.

2.2. Thoracic Aorta Homogenization. A sample from thoracic aorta was taken for homogenization in liquid nitrogen, it was mixed with a sucrose solution in the presence of protease inhibitors ( $1 \mathrm{mM}$ PMSF, $2 \mu \mathrm{M}$ pepstatin A, $2 \mu \mathrm{M}$ leupeptin, and $0.1 \%$ aprotinin), and the preparation was kept on ice. The thoracic aorta homogenate was centrifuged at $900 \times$ $\mathrm{g}$ for $10 \mathrm{~min}$ at $4^{\circ} \mathrm{C}$. The supernatant was separated and kept at $-70^{\circ} \mathrm{C}$ until required. Protein concentration in the thoracic aorta homogenate was determined by the method of Lowry et al. [44].

2.3. Immunofluorescence. $3 \mathrm{~mm}$ of aortic sections was quickly frozen in Tissue-Tek (Sakura Finetek USA, Inc., Torrance, CA). Sections were fixed with acetone and were blocked with PBS/azide $0.02 \% / B S A ~ 1 \%$ for $30 \mathrm{~min}$.

Subsequently, these sections were left for 2 hours at room temperature with a rabbit polyclonal antibody against type IV collagen ( $1: 20)$, fibronectin, laminin $-\gamma-1$, iNOS, and eNOS (1:50; Santa Cruz Biotechnology, Inc., Santa Cruz, CA). Primary antibodies were detected with goat, anti-rabbit, FITC (Jackson ImmunoResearch Laboratories Inc., West Grove, $\mathrm{PA}$ ), at room temperature for $60 \mathrm{~min}$. Negative controls were prepared by substituting the primary antibody with an irrelevant antibody. Immunofluorescence was examined using a fluorescence microscope (Nikon Eclipse TE2000-U, Digital Nikon sight chamber D5-U3). Images were processed with SigmaScan Pro program, Image Analysis version 5.0.0, 1987-1999 SPSS Inc. 
TABLE 1: Demographic characteristics of the patients.

\begin{tabular}{|c|c|c|c|c|c|c|}
\hline Characteristics & $\begin{array}{c}\text { Control } \\
n=4\end{array}$ & $\begin{array}{c}\text { SAH } \\
n=11\end{array}$ & $\begin{array}{c}\text { Marfan's variants } \\
n=4\end{array}$ & $\begin{array}{c}\text { Classic } \\
\text { Marfan } \\
n=9\end{array}$ & $\begin{array}{l}\text { Turner's syndrome } \\
\qquad n=2\end{array}$ & $\begin{array}{c}\text { Takayasu's arteritis } \\
n=2\end{array}$ \\
\hline Median age (range) & $59(42-62)$ & $59(34-72)$ & $46(28-55)$ & $30(17-56)$ & $33(31-34)$ & $33(26-40)$ \\
\hline Women $n(\%)$ & $1(25)$ & $4(37)$ & $1(25)$ & $4(44)$ & $2(100)$ & $2(100)$ \\
\hline Men $n(\%)$ & $3(75)$ & $7(64)$ & $3(75)$ & $5(56)$ & 0 & 0 \\
\hline Median BMI (range) & $22(18-24)$ & $31(30-32)$ & $24(23-32)$ & $22(17-30)$ & $28(23-32)$ & $19(16-23)$ \\
\hline Median LVEF (range) & $44(30-65)$ & $45(25-65)$ & $60(56-75)$ & $50(40-65)$ & $59(50-67)$ & $65(65-65)$ \\
\hline Median aortic diameter (range) & $55(55-55)$ & $52(26-65)$ & $66(62-70)$ & $75(55-120)$ & $81(67-96)$ & $50(50-50)$ \\
\hline $\mathrm{SAH} n(\%)$ & $1(50)$ & $11(100)$ & $1(25)$ & $2(22)$ & $2(100)$ & $1(50)$ \\
\hline Tobacco smoking $n(\%)$ & $1(50)$ & $4(37)$ & $2(100)$ & $2(22)$ & 0 & $1(50)$ \\
\hline
\end{tabular}

SAH: systemic arterial hypertension, BMI: body mass index, and LVEF: left ventricular ejection fraction.

2.4. Lipoperoxidation (LPO). LPO, a marker of damage by free radicals, was measured by a standard method [45]. One $\mathrm{mg}$ of protein from the thoracic aorta homogenate was used.

2.5. Superoxide Dismutase (SOD) Activity. SOD enzyme activity was determined in the thoracic aorta homogenate by nondenaturing gel electrophoresis and nitroblue tetrazolium staining as described by Flohe and Otting [46]. $60 \mu \mathrm{g}$ of the thoracic aorta homogenate was used. SOD activity was 5600 units/mg, calculated following the technique described by Pérez et al. [45]. Riboflavin and TEMED in the presence of UV light and oxygen produce ROS; nitroblue tetrazolium and SOD compete with them. Where SOD is present, the gel remains transparent, whereas reduced nitroblue tetrazolium turns it into purple-blue.

2.6. Catalase (CAT) Activity. $60 \mu \mathrm{g}$ of thoracic aorta homogenate was analyzed by native-gel electrophoresis with $8 \%$ polyacrylamide [47]. Protein CAT activity was 25000 units/mg, calculated following the technique described by Pérez et al. [45]. The gels of CAT and SOD were analyzed by densitometry by the image analyzer with SigmaScan Pro program, Image Analysis version 5.0.0, 1987-1999 SPSS Inc.

2.7. Assay of Glutathione S-Transferase (GST). The specific activity of cytosolic GST was determined spectrophotometrically at $340 \mathrm{~nm}$ by the method of Beutler [48]. $100 \mu \mathrm{g}$ from aorta homogenate was used per sample. The specific activity of GST is expressed in micromoles of CDNB-GSH conjugate formed $/ \mathrm{min} / \mathrm{mg}$ protein.

2.8. Assay of Glutathione Peroxidase (GPx). The enzyme GPx activity was measured spectrophotometrically at $340 \mathrm{~nm}$ by the method of Flohé and Günzler [49]. $100 \mu \mathrm{g}$ from aorta homogenate was used per sample.

2.9. Nitrates and Nitrites. Nitrates and nitrites were measured spectrophotometrically at $540 \mathrm{~nm}$ by the method described by Pérez et al. [45]. $100 \mathrm{mg}$ of protein from aorta homogenate was used per sample.
2.10. Immunoblotting. $100 \mu \mathrm{g}$ from aorta homogenate was used per sample. The immunoblotting was done according to the method described by Pérez et al. [45]. A dilution of $1 / 500$ of the rabbit primary IgG polyclonal antibodies against eNOS, iNOS, laminin- $\gamma-1$, and COL4A2 (NOS3 antibody rabbit IgG [C-20]: sc-654, NOS2 antibody rabbit IgG [C19]: sc-649, laminin- $\gamma-1$ antibody rabbit IgG [H-190]: sc-5584, and COL4A2 antibody rabbit IgG [N-14]: sc-70244; Santa Cruz Biotechnology, Inc.) was used.

2.11. Statistical Analysis. A descriptive analysis was performed. Univariate test includes age, gender, pathology types, and variables, and dichotomic and nominal variables were described as relative frequencies (percentages) and compared by chi-squared distribution or Fisher's exact test, as convenient. For bivariate analysis, continuous quantitative variables of normal distribution were compared by $t$ student, and nonparametric ones by Mann-Whitney $U$ test.

\section{Results}

3.1. General Characteristics. Out of the 32 patients, 14 were women, and 18 were men. The demographical characteristics of the patients are shown in Table 1 , and the clinical data are shown in Table 2.

Measurements were made individually and they were grouped afterwards to be analyzed.

3.2. Lipoperoxidation. Aortic tissues from patients with $\mathrm{SAH}$, MV, M, Turner's syndrome, and TA showed significantly increased LPO $(P \leq 0.05)$, when compared to $\mathrm{C}$ subjects (Figure 1).

3.3. Activity of Antioxidant Enzymes. In SAH, MV, M, and Turner's syndrome, aortas showed an increase in Mn-SOD activity and $\mathrm{Cu}-\mathrm{Zn}-\mathrm{SOD}(P<0.05)$ in comparison to $\mathrm{C}$ subjects (Figures 2(a) and 2(b)). CAT activity increased in $\mathrm{M}$ and Turner's syndrome patients $(P=0.05)$ in comparison to $\mathrm{C}$ subjects (Figure 3). Figure 4(a) shows the GPx activity in SAH, MV, M, Turner's syndrome, and TA patients which was significantly increased $(P<0.05)$ when compared to $\mathrm{C}$ 
TABLE 2: Clinical finding, surgery type, and report diameters aortic.

\begin{tabular}{|c|c|c|c|c|}
\hline Sex & Age & Diagnosis & Clinical findings & Aortic diameter mm \\
\hline $\mathrm{H}$ & 68 & SAH & SVAo and aortic reduction plastic & 26 \\
\hline M & 55 & $\mathrm{SAH}$ & Aortic dissection and Ao. I (BB) & 55 \\
\hline $\mathrm{H}$ & 63 & SAH & Hypertensive cardimyopathy and abdominal aneurysm (BB) & 55 \\
\hline $\mathrm{H}$ & 59 & SAH & Aortic arc substitution and stent subclavian artery (BB) & 69 \\
\hline M & 53 & $\mathrm{SAH}$ & Aortic root aneurysm $(\mathrm{BB})$ & 50 \\
\hline $\mathrm{H}$ & 46 & SAH & $\begin{array}{l}\mathrm{B} \text { and } \mathrm{B} \text { aortic arc substitution and revascularization of } \\
\text { brachiocephalic trunk }\end{array}$ & 55 \\
\hline M & 59 & SAH & Ascending aorta dissection (BB) & 60 \\
\hline M & 55 & $\mathrm{SAH}$ & $\begin{array}{l}\text { Aortic valve substitution }+ \text { plastia aorta }+ \text { Revascularization } \\
\text { Coronary: Internal thoracic artery-DA, Venous Hemoduct }\end{array}$ & 65 \\
\hline $\mathrm{H}$ & 34 & $\mathrm{SAH}$ & Abdominal aneurysm (BB) & 100 \\
\hline $\mathrm{H}$ & 72 & SAH & $\begin{array}{l}\mathrm{B} \text { and } \mathrm{B} \text { aortic arc substitution and revascularization of } \\
\text { brachiocephalic trunk }\end{array}$ & 70 \\
\hline $\mathrm{H}$ & 63 & SAH & Ascending aortic aneurysm (David) & 51 \\
\hline $\mathrm{H}$ & 31 & Marfan's syndrome & Ascending Ao. A, coarctation. Bivalve aorta (BB) & 75 \\
\hline $\mathrm{H}$ & 17 & Marfan's syndrome & Aortic dissection and aortic insufficiency (BB) & 87 \\
\hline $\mathrm{H}$ & 56 & Marfan's syndrome & Aortic dissection and aortic insufficiency (BB) & 94 \\
\hline $\mathrm{H}$ & 17 & Marfan's syndrome & Aortic dissection and Ao. A (BB) & 68 \\
\hline $\mathrm{H}$ & 42 & Marfan's syndrome & Aortic dissection and Ao. A (BB) & 120 \\
\hline M & 38 & Marfan's syndrome & Aortic dissection and Ao. A (BB) & 55 \\
\hline M & 21 & Marfan's syndrome & Aortic ascending aneurysm (BB) & 67 \\
\hline $\mathrm{H}$ & 23 & Marfan's syndrome & Bicuspid aortic valve and ascending aorta $\mathrm{A}(\mathrm{BB})$ & 96 \\
\hline $\mathrm{H}$ & 23 & Marfan's syndrome & Aortic root dilation and aneurysm (BB) & 50 \\
\hline M & 28 & Marfan's variant & Ascending aorta aneurysm (BB) & 88 \\
\hline $\mathrm{H}$ & 46 & Marfan's variant & Ascending aorta aneurysm (BB) & 70 \\
\hline $\mathrm{H}$ & 46 & Marfan's variant & Thoracic aneurysm and ascending aorta (BB) & 55 \\
\hline $\mathrm{H}$ & 55 & Marfan's variant & Ascending aortic and aortic root aneurysm (BB) & 57 \\
\hline M & 31 & Turner's syndrome & Ascending aorta aneurysm and infradiaphragmatic aorta (By) & 67 \\
\hline M & 34 & Turner's syndrome & Acute aortic syndrome and dissection (BB) & 100 \\
\hline M & 26 & Takayasu’s arteritis & Acute aortic syndrome and dissection of aneurysm (BB) SVAo & 54 \\
\hline M & 40 & Takayasu's arteritis & Autopsia complications of IRCT & 52 \\
\hline $\mathrm{H}$ & 62 & Control & Aortic stenosis & 50 \\
\hline M & 60 & Control & Aortic stenosis & 54 \\
\hline $\mathrm{H}$ & 42 & Control & Aortic stenosis & 52 \\
\hline $\mathrm{H}$ & 60 & Control & Aortic stenosis & 60 \\
\hline
\end{tabular}

F: female, M: man, Ao. A: aortic aneurysm, SAH: systemic arterial hypertension, Ao. I: aortic insufficiency, BB: surgery Bental and Bono, David: David surgical procedure, Descending artery: DA, SVAo: aortic valve substitution.

subjects. Figure 4(b) shows the GST activity in SAH, MV, M, Turner's syndrome, and TA. It was significantly increased in these groups $(P<0.05)$ when compared to $C$ subjects.

3.4. Endothelial Nitric Oxide Synthase and $\mathrm{NO}_{3}{ }^{-} / \mathrm{NO}_{2}{ }^{-}$. In patients with $\mathrm{SAH}, \mathrm{MV}$, and $\mathrm{M}$, eNOS expression was elevated $(P=0.01)$ in comparison to $\mathrm{C}$ subjects (Figure 5(a)). $\mathrm{NO}_{3}{ }^{-} / \mathrm{NO}_{2}{ }^{-}$significantly increased in SAH and TA $(P=$ 0.01 ) in comparison to $\mathrm{C}$ subjects (Figure 5(b)).

3.5. Variations in Structural and Functional Proteins. Figure 6(a) shows the localization of type IV collagen in aortas from patients. A decrease in type IV collagen was observed in Turner's syndrome and TA $(P=0.01)$ when compared to $\mathrm{C}$ subjects. Fibronectin did not show changes in any group (results not shown). Figure 6(b) shows that laminin- $\gamma-1$ in aorta of $\mathrm{MV}$ was decreased while in $\mathrm{M}$ patients it was increased $(P=0.03)$ when compared to $\mathrm{C}$ subjects.

3.6. Inducible Nitric Oxide Synthase. In patients with SAH, MV, M, Turner syndrome, and TA iNOS expression was elevated $(P<0.05)$ in comparison to $\mathrm{C}$ subjects (Figure 7$)$.

3.7. Immunoblotting. Figure 8 shows eNOS, iNOS, type IV collagen, and laminin- $\gamma$-1 expression in the homogenized 


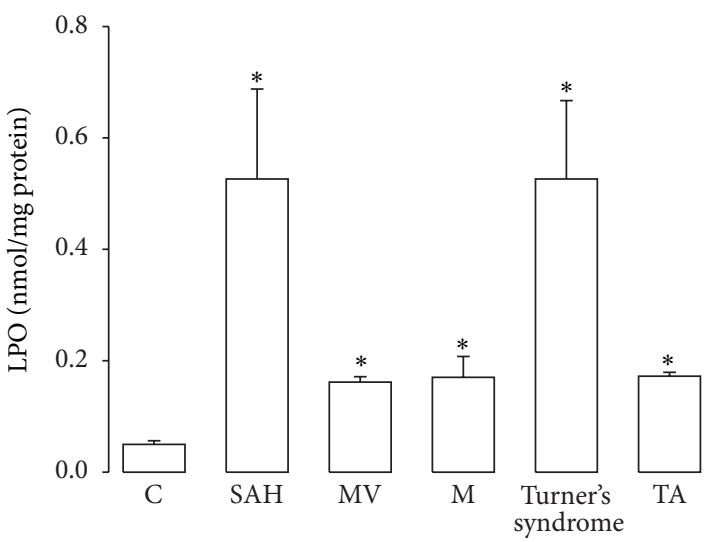

FIGURE 1: Comparison of LPO results in control subjects and in patients with the different pathologies studied. ${ }^{*} P \leq 0.05$; C versus SAH, MV, M, Turner's syndrome, and TA. Abbreviations: SAH: systemic arterial hypertension; MV: variants of Marfan's syndrome; M: Marfan's syndrome; Turner's syndrome; and TA: Takayasu's arteritis.

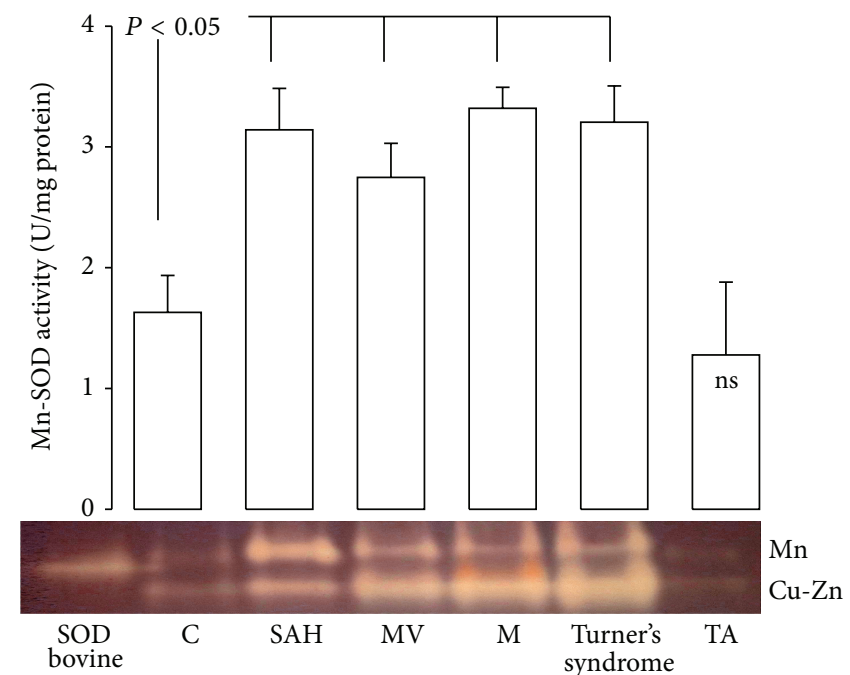

(a)

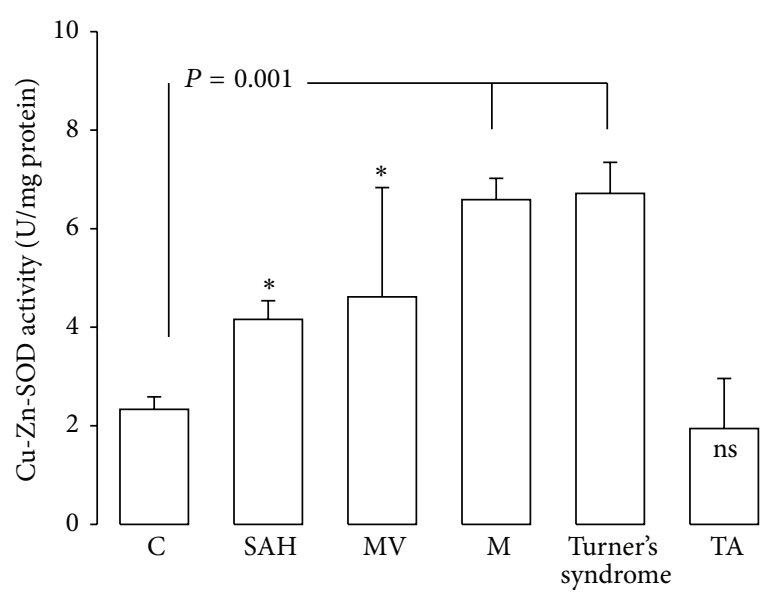

(b)

Figure 2: Mn-SOD and $\mathrm{Cu}-\mathrm{Zn}$-SOD activity in control subjects and in patients with the different pathologies studied. ${ }^{*} \mathrm{P} \leq 0.05$; $\mathrm{C}$ versus $\mathrm{MV}$ and SAH.

aorta from the patients with aortopathies. The eNOS, iNOS, type IV collagen, and laminin- $\gamma-1$ expression showed the same trend as the one found by immunofluorescence.

\section{Discussion}

The mechanisms through which oxidative stress and inflammatory processes might produce vascular abnormalities are unknown. In this paper we studied variations in the activity of antioxidant enzymes and in structural and functional proteins in several illnesses in which there is vascular dysfunction and altered mechanical properties that lead to pseudoaneurysms/aneurysms or obstruction. The disease renders it necessary for the patients to undergo surgery. The exact source of ROS and RNS in the pathophysiological pathways of these pathologies has not been clearly described.
ROS and LPO lead to DNA oxidative damage and to high levels of 8-iso- prostaglandin $\mathrm{F}_{2 \alpha}$ (8- iso- $\mathrm{PGF}_{2 \alpha}$ ) in patients having essential hypertension [50]. Serum of patients with TA shows a similar tendency [51]. The role of ROS in the onset and progression of aortic damage has been described in animal models of different illnesses [52] and ROS are important mediators in the signaling pathways of inflammation and atherogenesis [53, 54]. An imbalance between the prooxidative agents and antioxidants leads to changes in the redox state. Mouse models for $M$ have vasomotor dysfunction in the thoracic aorta associated with oxidative stress, which correlates with an increase in eNOS and a diminished production of $\mathrm{Mn}-$ and $\mathrm{Cu}-\mathrm{Zn}-\mathrm{SOD}[4$, 55]. Our results show an increase in $\mathrm{Mn}-\mathrm{SOD}$ and $\mathrm{Cu}-\mathrm{Zn}$ SOD activity in SAH, MV, M, and Turner's syndrome. The increased expression and activity found suggest that, due 


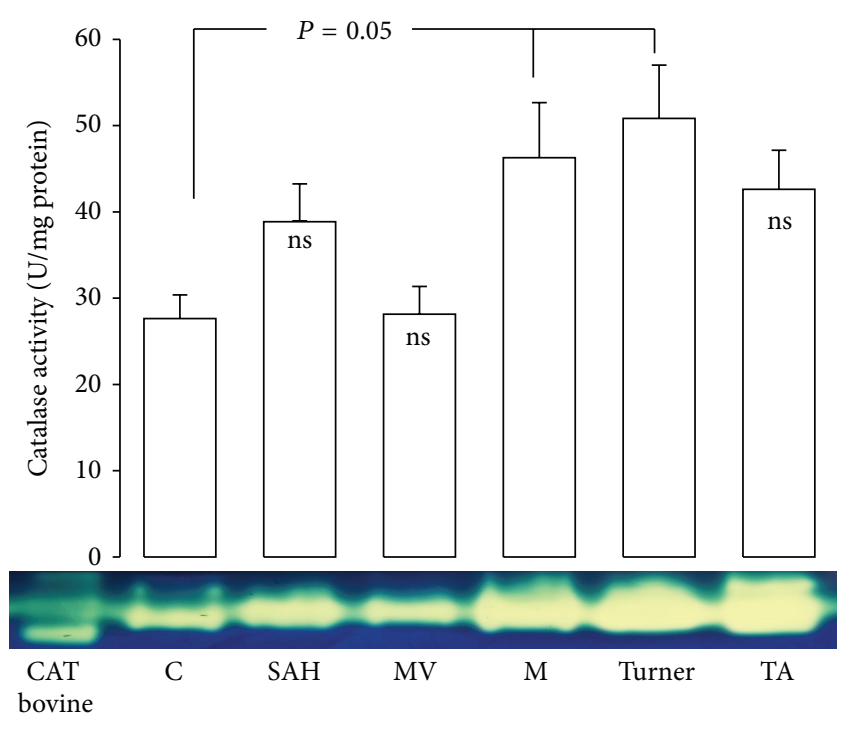

FIGURE 3: Catalase activity in control subjects and in patients with the different pathologies studied.

to the increase in oxidative stress, the patient's antioxidant system is overexpressed in an attempt to counteract the imbalance. The vascular protection by the expression and activity of the isoforms of the SOD in the vascular wall has been evaluated in mouse models, finding either SOD deficiency or overproduction [56]. An increase in vascular permeability or reperfusion injury after ischemia is related to SOD deficiency, and the overexpression of the $\mathrm{Cu}-\mathrm{Zn}$ SOD protects against reperfusion injury [57]. Also, cytosolic and extracellular SOD expression alterations might impact on vascular and other tissue structures, because they inhibit vascular and myocardial hypertrophy [58].

The beneficial function of SOD as antioxidant in diverse illnesses [59] both in animal models and in patients with or without an active inflammatory disease has been described [60]. The mechanisms inducing inflammation may act through different stimulus and receptors among which the type 1 angiotensin receptor seems to play an important role [61]. Our results showed an increase in $\mathrm{Mn}-$ and $\mathrm{Cu}-\mathrm{Zn}-$ SOD enzyme activity in SAH, MV, M, and Turner's syndrome without significant changes in TA when compared to $\mathrm{C}$ subjects. These results suggest that SOD isoforms increase their activity to protect against oxidative stress.

SOD isoforms are important within the vascular wall in normal conditions and in diseased states in humans. $\mathrm{Cu}-\mathrm{Zn}$-SOD expression is relatively high in all cell types, including blood cells, and it accounts for $50 \%$ to $80 \%$ of the total activity, being, therefore, the predominant isoform. MnSOD is responsible for $2 \%$ of the activity and the remaining $12 \%$ of the activity may be due to extracellular SOD (SOD$\mathrm{EC})$. The functional importance of $\mathrm{Cu}-\mathrm{Zn}-\mathrm{SOD}$ is further evidenced when there is deficiency of SOD-EC [62]. In mice with $\mathrm{Cu}-\mathrm{Zn}$-SOD deficiency there is an increase in vascular permeability and ischemia related to hypertrophy of cerebral arterioles [63]. In our study, the Cu-Zn-SOD deficiency found in hypertensive patients with aortic dilatation, Turner's syndrome, and TA could be related to vascular alterations and to the clinical condition of these patients. In genetically modified mice with $\mathrm{Cu}-\mathrm{Zn}$-SOD overexpression there is a protective effect against vascular dysfunction [64].

Under normal conditions, Mn-SOD is the first line of defense against oxidative stress. Its localization, induction mechanisms, vascular expression, and activity are known [65] and might be altered under physiological and pathophysiological conditions, particularly under overregulation of oxidative stress [66]. Mn-SOD expression is altered at certain stages of disease that are associated with vascular oxidative stress.

Proinflammatory cytokines and LPS-mediated inflammation in vascular tissue cause an increase in superoxide $\left(\mathrm{O}_{2}{ }^{-}\right)$production and in $\mathrm{Mn}$-SOD expression [67]. In atherosclerosis, vascular expression of $\mathrm{Cu}-\mathrm{Zn}-\mathrm{SOD}$ and $\mathrm{Mn}-$ SOD mRNA increases at the onset of the disease and diminishes over time [68]. In chronic hypertensive models, the expression of vascular Mn-SOD is also increased [69]. There are many conditions that elevate peroxynitrite concentrations which, in turn, inactivate Mn-SOD. These include inflammation, diabetes, hypertensive atherosclerosis, subarachnoid hemorrhage, and age. However, in recent studies, Mn-SOD was found to protect from mitochondrial vascular damage and atherosclerosis development [70].

In this study, all of the aortopathy groups had an increase in $\mathrm{Mn}$ - and $\mathrm{Cu}-\mathrm{Zn}$-SOD, which correlated with increased LPO with the exception of TA. Mn-SOD overexpression reduces superoxide levels [71] and improves endothelial function in some models, thereby preventing endothelial injury [72]. Moreover, we consider that, in these patients, the compensatory mechanisms were diminished and oxidative stress was increased. In other vascular illnesses, these compensatory response mechanisms vary and could be associated with other factors such as evolution of the pathology, etiopathogenic mechanisms, and host response capacity [73]. TA is associated with tuberculosis infection which has only been proven in isolated cases [74-77]. In patients with confirmed tuberculosis, an important decrease in Mn-SOD has been found, which improves with treatment [78]. Recent studies proposed Mn-SOD as an important antioxidant modulator after vascular injury. These results suggest that it might be employed as a promising therapeutic strategy for vascular injury prevention and in proliferative diseases where there is stenosis [79].

CAT is another important antioxidant enzyme, which is found in the liver, kidney, and aorta. CAT uses two $\mathrm{H}_{2} \mathrm{O}_{2}$ molecules to break them into $\mathrm{O}_{2}^{-}$; one acts as a reducing agent and the other as an oxidant. Overexpression of CAT prevents the stimulation of ROS [80]. Our results showed that CAT increased in the patients with $\mathrm{M}$ and Turner's syndrome. These results suggest that overexpression of CAT may be due to overproduction of $\mathrm{H}_{2} \mathrm{O}_{2}$ in the aorta from these patients. The increase in CAT activity in our study may be attributed, in part, to continuous exposure to hydroperoxides. Although different studies have shown that in hypertension CAT activity is low [81], in our study CAT activity showed no significant change in SAH, MV, and TA when compared to C subjects. 


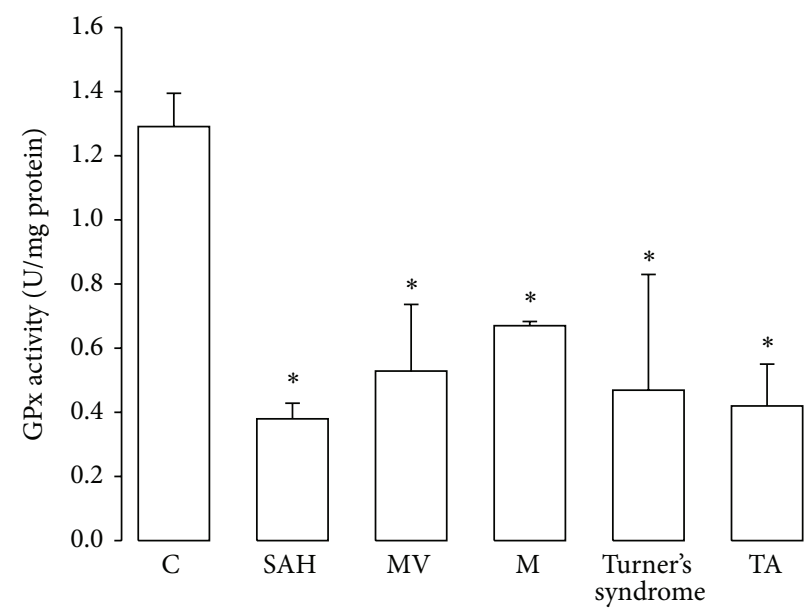

(a)

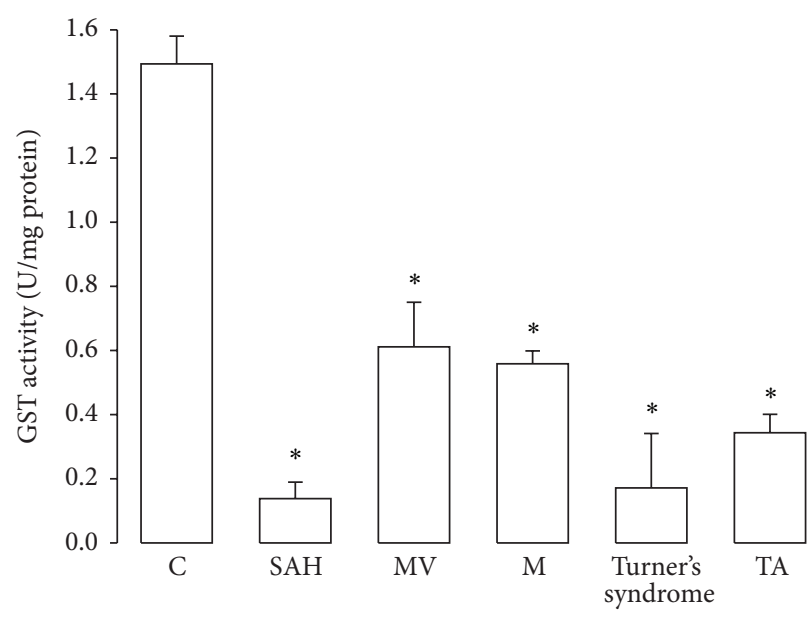

(b)

Figure 4: Glutathione peroxidase and glutathione S-transferase activity in controls and in the pathologic conditions studied. ${ }^{*} P=0.05$, $\mathrm{C}$ versus SAH, MV, M, Turner's syndrome, and TA. Abbreviations: SAH: systemic arterial hypertension, MV: variants of Marfan's syndrome, M: Marfan's syndrome; Turner's syndrome; and TA; Takayasu's arteritis.

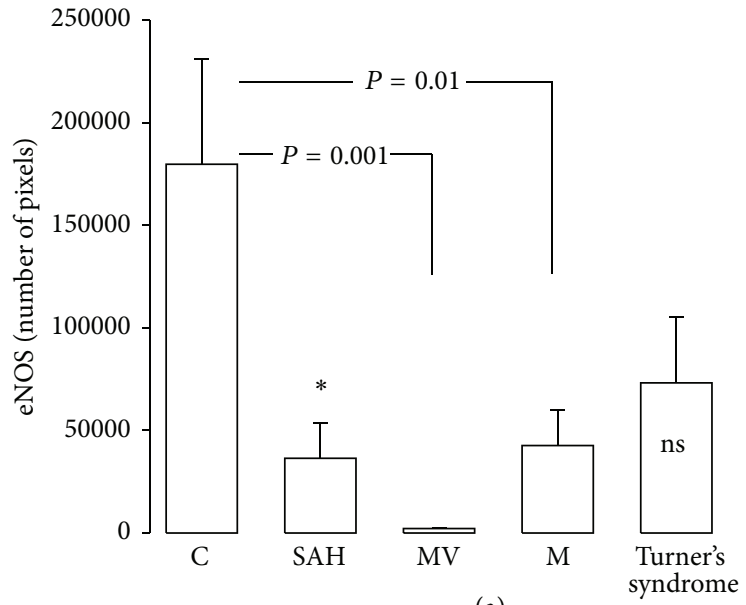

(a)

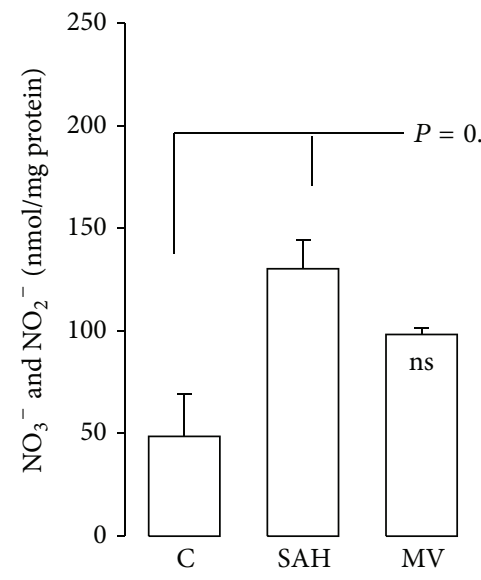

(b)
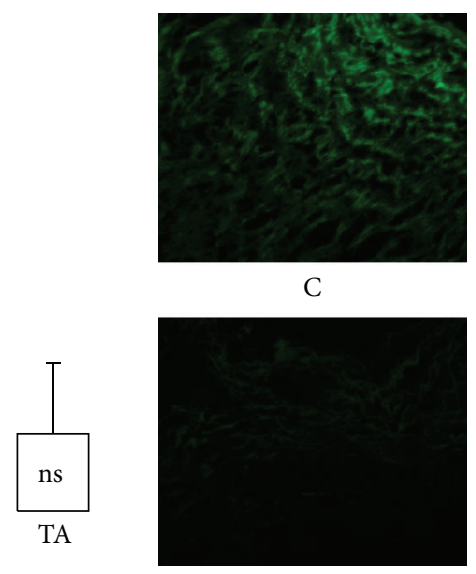

SAH
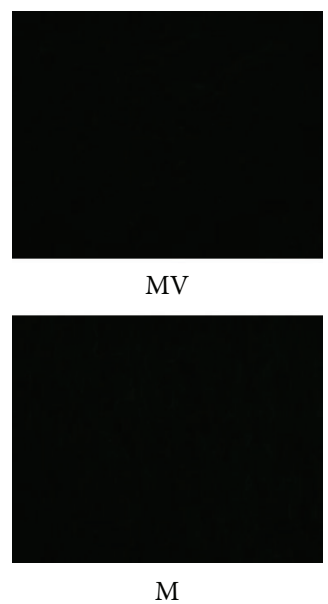

Figure 5: Comparison of the eNOS activity and $\mathrm{NO}_{3}{ }^{-} / \mathrm{NO}_{2}{ }^{-}$in control subjects and in patients with the different pathologies studied ${ }^{*} P=$ $0.05, \mathrm{C}$ versus SAH. Pictures show the eNOS immunofluorescence that were significantly different. 


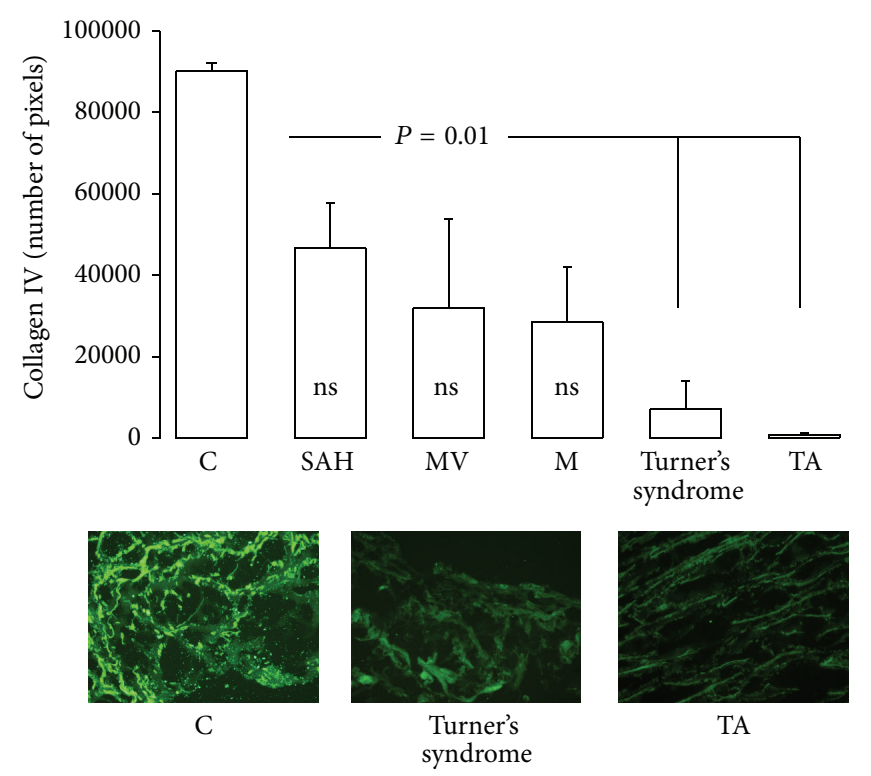

(a)

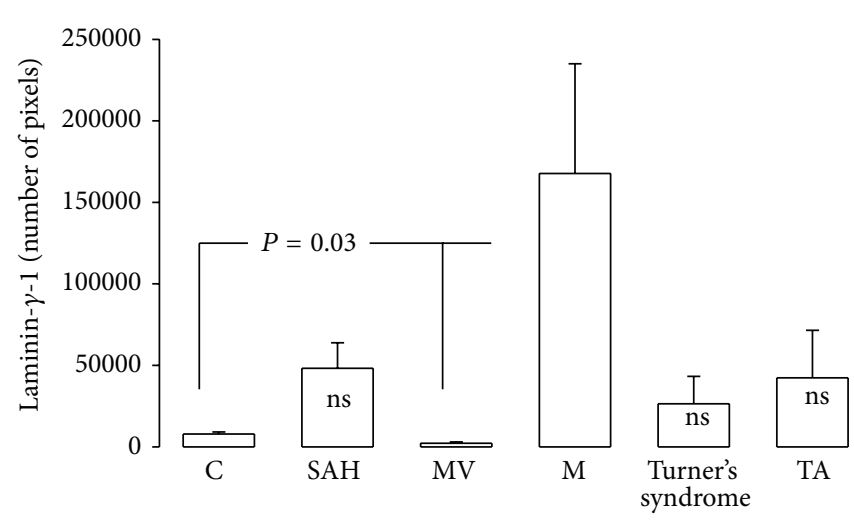

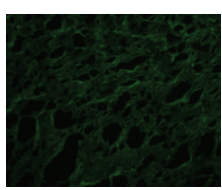

C

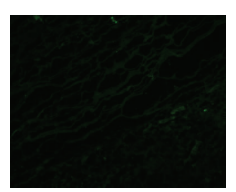

MV

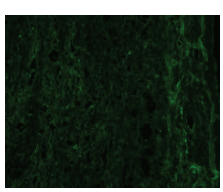

M (b)

FIGURE 6: Immunofluorescence results for collagen and laminin- $\gamma$-1 in control subjects and in patients with the different pathologies studied. Pictures show type IV collagen and laminin- $\gamma$-1 immunofluorescence with statistically significant differences.

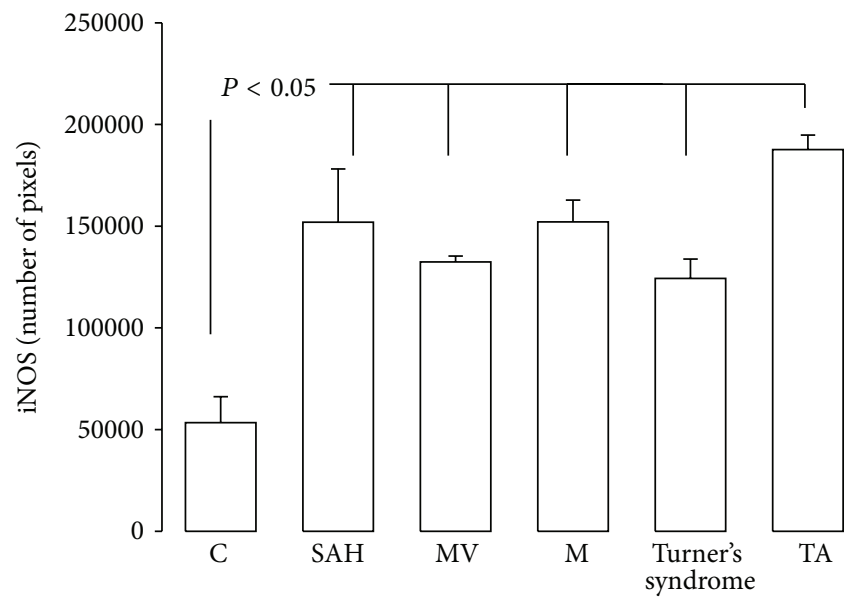

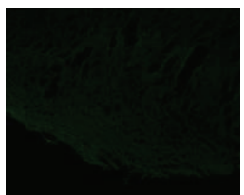

C

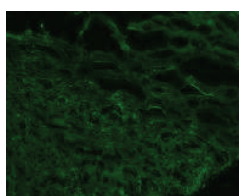

SAH

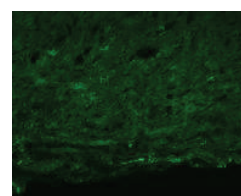

MV

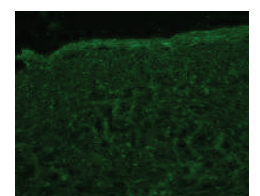

M

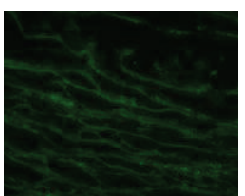

Turner's syndrome

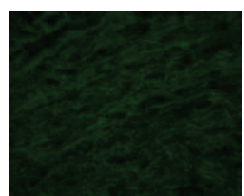

TA

FIGURE 7: Immunofluorescence results and comparison of the iNOS expression in control subjects and in patients with the different pathologies studied. Pictures show the iNOS immunofluorescence with significant differences.

The enzyme GST conjugates GSH to electrophilic xenobiotics, chemicals, and toxic compounds like malondialdehyde which is an end product of the LPO process in phospholipids, leading to an increase in the rigidity of the cellular membrane, forming a thioether bond [82]. Patients with hypertension usually show a decrease in GST activity [83]. Our results show a decrease in GST activity in SAH, MV, M, Turner's syndrome, and TA in comparison to C subjects. A similar tendency was found in GPx activity. GPx detoxifies low levels of hydrogen peroxide with the help of GSH, causing its 


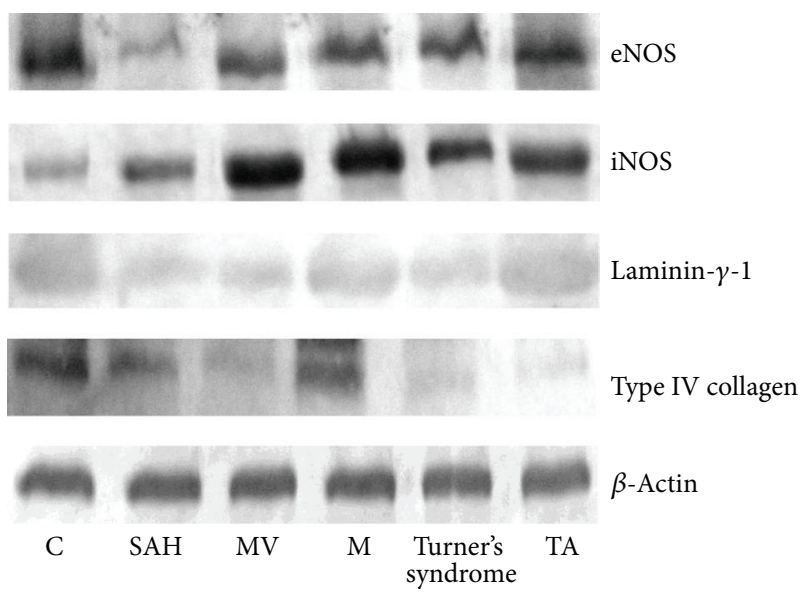

FIGURE 8: eNOS, iNOS, type IV collagen, and laminin- $\gamma$-1 expression in homogenized aorta. Abbreviations: SAH: systemic arterial hypertension, MV: variants of Marfan's syndrome, M: Marfan's syndrome, Turner's syndrome, and TA: Takayasu's arteritis.

oxidation [84]. Hypertension is associated with decreased activity of many antioxidant enzymes including GST and GPx.

GPx can also be inactivated in conditions of oxidative stress; $\mathrm{O}_{2}^{-}$can inhibit the function of this enzyme [83]. These results suggest that the decrease in GST and GPx activity can be due to oxidative stress in these patients. In this study we did not analyze glutathione concentration, but the decrease in GPx and GST activity may be due in part to a decrease of glutathione and to the accumulation of ROS. When hypertension advances into stages II and III, even the defense of GPx might deteriorate because of the increased production of ROS [85].

LPO is increased in animal models, in serum from patients with atherosclerosis [86], and in TA. Our results show that LPO is increased in SAH, MV, M, Turner's syndrome, and TA, which is consistent with previous reports in the literature [87]. In essential hypertension and $M$ an increase in the LPO levels in comparison to healthy subjects has been described $[88,89]$ ]. 8-iso-PGF $2 \alpha$, a marker of stress oxidative, also increases in TA [37]. Our results on MDA levels suggest that the pathologies studied show a different grade of oxidative stress with respect to $C$ subject, modifying the activity of the antioxidant enzyme system.

The endothelium constitutively releases a number of vasoactive mediators including $\mathrm{NO}$ that regulate smooth muscle contractility and thus vascular smooth muscle tone and mechanical properties. Endothelial dysfunction and downregulated NO would contribute to the stiffness, the reduced distensibility, and the aortic complications that have been described in MV and M in mice models. Alteration of fibrillin-1 impairs the integrity of elastic fibers within the endothelial layer and endothelial permeability is impaired in $\mathrm{M}$ [90]. The reduction of NO production also decreases cGMP levels which act as downstream second messengers of NO signaling. In addition, MV and $\mathrm{M}$ are associated with elevated plasma levels of homocysteine, which attenuates endothelial function and limits NO bioavailability, production, and reduction. NO alterations increase the susceptibility to aortic complications [91]. Our results showed that $\mathrm{SAH}, \mathrm{MV}$, and $\mathrm{M}$ showed a decrease in eNOS expression. These results suggest that eNOS metabolism is decreased and that its participation is reduced in these pathologies. An explanation for the decline of eNOS is that the highly oxidative environment decreases its activity. However, our results show an increase of the $\mathrm{NO}_{3}{ }^{-}$and $\mathrm{NO}_{2}{ }^{-}$ratio, which are metabolites of NOS. The increase in $\mathrm{NO}_{3}{ }^{-}$and $\mathrm{NO}_{2}{ }^{-}$ratio may be due to inducible nitric oxide synthase (iNOS); this enzyme could be a mediator in some stages of the disease [92]. The immunofluorescence shows an increase of iNOS expression in all of the pathologies studied in comparison to control subjects. These results suggest that iNOS produces NO mainly during inflammatory processes and iNOS contributes significantly to the tissue $\mathrm{NO}_{3}{ }^{-} / \mathrm{NO}_{2}{ }^{-}$ratio. It may participate in protein matrix degradation and play a causal role in aneurysm formation [93]. iNOS is widely expressed in diverse cell types that are under transcriptional regulation by inflammatory mediators and has been implicated in the pathogenesis of many disorders including atherosclerosis, stroke, arthritis, and aneurisms [94].

In the pathologies studied, the presence of aneurisms contributes to endothelial dysfunction and the increase in the $\mathrm{NO}_{3}{ }^{-}$and $\mathrm{NO}_{2}{ }^{-}$ratio can favor the increase of peroxynitrites. In addition, altered NO bioavailability contributes to the modified vasomotion in hypertension [95] where an increased production of ROS is associated with an elevated production of peroxynitrite in coronary blood vessels. Endothelial dysfunction also promotes an increase in the generation of $\mathrm{O}_{2}^{-}$leading to an enhanced NO inactivation against peroxynitrites [93]. Additionally, peroxynitrites impair NO production through oxidation of $\mathrm{BH}_{4}$, a NOS cofactor [96]. Furthermore elevated peroxynitrites are associated with elevations in the myogenic tone, vasoconstriction, and deterioration of the endothelium-mediated relaxation [64].

Our results show significant changes in some proteins of the extracellular matrix such as laminin- $\gamma-1$ and type IV collagen. A decrease in these proteins could explain, at least in part, the deterioration of vascular mechanical function in these patients. Oxidative stress could deteriorate the endothelium and favor the synthesis of subendothelial proteins. In animal models, changes in the signaling pathways promote alterations such as proliferation, migration, and remodeling of the extracellular matrix in vascular smooth muscle cells having as a consequence an increase in vascular wall thickness, inflammation, and susceptibility to develop atherosclerosis. Some animal models have been proposed to explain the structural changes in vascular pathology [52]. However, it is not clear if these mechanisms operate in a similar way in human tissues [97].

Finally, this study has, as an important limitation, the use of aortas from patients with rare conditions. This renders impractical the monitoring of each patient prospectively for a long time. The retrospective study only allows the evaluation of some aspects but does not give the opportunity to correct 
some biases. Prospective studies should be undertaken in a systematic way to evaluate several aspects such as the role of the oxidative stress, antioxidant therapy, and participation of factors in reducing aortic dilatation.

The relevance of this study lies in the presence of aneurysms and cardiovascular damage as an outcome in all of the conditions studied. It stimulates research interest in intervention maneuvers and preventive aspects. The study generates hypothesis from the genetic, environmental, and therapeutical points of view. The major limitation of this study is the small size of the aortic sample in diseases like MV, $\mathrm{M}$, Turner's syndrome, and TA that occur with an incidence of 2-3 per 10000 individuals, being autosomal dominant disorders of the connective tissue caused by mutations. Furthermore, the causal associations between cellular and mechanical processes in the formation of aortic aneurysms have not been completely defined, so that a specific therapy has not been proposed. However, some studies have shown that simvastatin decreases free radicals, NF- $\kappa \mathrm{B}$, and improves the antioxidant condition [98]. In this study, patients with $M$ had an increase in CAT that could be associated with laminin, but this could be due to the fact that they were receiving simvastatin. In some cases with TA, hypertension, and myocardial ischemic injury, LPO was increased and antioxidant enzymes decreased, suggesting an increase in the production of ROS. In this group none of the patients received simvastatin; this observation sets up a possible future therapeutic hypothesis in these cohorts.

\section{Conclusions}

These preliminary findings show similarities and differences in the role of oxidative stress in the pathologies studied. It is necessary to implement appropriate studies and methodological strategies to assess oxidative stress in each condition, as each pathogenesis can influence the cellular redox state. Prooxidant damage mechanisms seem to be specific and a common pathway for injury and aortic deterioration. Compensatory mechanisms, in chronic stages of aortic damage, are inversely related, since in the presence of LPO there is a low antioxidant activity. However, in early stages, prooxidant and antioxidant agents seem to develop in parallel, as a response to the imbalance. In these pathologies, whose ultimate damage is the aorta, therapeutic maneuvers acting upon antioxidants should be started since diagnosis, independent of the cause of aortic damage. The cohort design, retrospective and prospective, should be appropriate for each group.

\section{Abbreviations}

CAT: Catalase

SOD: Superoxide dismutase

GPx: Glutathione peroxidase

GST: Glutathione S-transferase

ROS: Reactive oxygen species

eNOS: Endothelial nitric oxide synthese

iNOS: Inducible nitric oxide synthese

LPO: Lipoperoxidation.

\section{Conflict of Interests}

The authors declare that there is no conflict of interests regarding the publication of this paper.

\section{Acknowledgment}

The authors would like to thank Rodrigo Velázquez Espejel and Ana Beatriz Mártinez Cervantes for technical support in immunoblotting and immunofluorescence, respectively.

\section{References}

[1] Y. Xia, A.-L. Tsai, V. Berka, and J. L. Zweier, "Superoxide generation from endothelial nitric-oxide synthase: $\mathrm{a} \mathrm{Ca}^{2+} /$ calmodulindependent and tetrahydrobiopterin regulatory process," Journal of Biological Chemistry, vol. 273, no. 40, pp. 25804-25808, 1998.

[2] D. B. Sawyer, D. A. Siwik, L. Xiao, D. R. Pimentel, K. Singh, and W. S. Colucci, "Role of oxidative stress in myocardial hypertrophy and failure," Journal of Molecular and Cellular Cardiology, vol. 34, no. 4, pp. 379-388, 2002.

[3] C. Rush, M. Nyara, J. V. Moxon, A. Trollope, B. Cullen, and J. Golledge, "Whole genome expression analysis within the angiotensin II-apolipoprotein E deficient mouse model of abdominal aortic aneurysm," BMC Genomics, vol. 10, article 298, 2009.

[4] H. H. C. Yang, C. van Breemen, and A. W. Y. Chung, "Vasomotor dysfunction in the thoracic aorta of Marfan syndrome is associated with accumulation of oxidative stress," Vascular Pharmacology, vol. 52, no. 1-2, pp. 37-45, 2010.

[5] M. O. Kane, N. Etienne-Selloum, S. V. F. Madeira et al., "Endothelium-derived contracting factors mediate the Ang IIinduced endothelial dysfunction in the rat aorta: preventive effect of red wine polyphenols," Pflugers Archiv European Journal of Physiology, vol. 459, no. 5, pp. 671-679, 2010.

[6] S. Serpillon, B. C. Floyd, R. S. Gupte et al., "Superoxide production by $\mathrm{NAD}(\mathrm{P}) \mathrm{H}$ oxidase and mitochondria is increased in genetically obese and hyperglycemic rat heart and aorta before the development of cardiac dysfunction. The role of glucose6-phosphate dehydrogenase-derived NADPH," The American Journal of Physiology-Heart and Circulatory Physiology, vol. 297, no. 1, pp. H153-H162, 2009.

[7] K. Maiellaro-Rafferty, D. Weiss, G. Joseph, W. Wan, R. L. Gleason, and W. R. Taylor, "Catalase overexpression in aortic smooth muscle prevents pathological mechanical changes underlying abdominal aortic aneurysm formation," The American Journal of Physiology-Heart and Circulatory Physiology, vol. 301, no. 2, pp. H355-H362, 2011.

[8] H. Kaneko, T. Anzai, K. Horiuchi et al., "Tumor necrosis factor$\alpha$ converting enzyme is a key mediator of abdominal aortic aneurysm development," Atherosclerosis, vol. 218, no. 2, pp. 470478, 2011.

[9] J.-O. Deguchi, H. Huang, P. Libby et al., "Genetically engineered resistance for MMP collagenases promotes abdominal aortic aneurysm formation in mice infused with angiotensin II," Laboratory Investigation, vol. 89, no. 3, pp. 315-326, 2009.

[10] K. J. Davies, "Oxidative stress: the paradox of aerobic life," Biochemical Society symposium, vol. 61, pp. 1-31, 1995.

[11] R. Bolli, M. O. Jeroudi, B. S. Patel et al., "Marked reduction of free radical generation and contractile dysfunction by antioxidant therapy begun at the time of reperfusion: evidence that 
myocardial 'stunning'is a manifestation of reperfusion injury," Circulation Research, vol. 65, no. 3, pp. 607-622, 1989.

[12] J.-C. Charniot, D. Bonnefont-Rousselot, J.-P. Albertini et al., "Oxidative stress implication in a new ex-vivo cardiac concordant xenotransplantation model," Free Radical Research, vol. 41, no. 8, pp. 911-918, 2007.

[13] K. K. Griendling, D. Sorescu, and M. Ushio-Fukai, "NAD(P)H oxidase: role in cardiovascular biology and disease," Circulation Research, vol. 86, no. 5, pp. 494-501, 2000.

[14] K. K. Griendling, D. Sorescu, B. Lassègue, and M. Ushio-Fukai, "Modulation of protein kinase activity and gene expression by reactive oxygen species and their role in vascular physiology and pathophysiology," Arteriosclerosis, Thrombosis, and Vascular Biology, vol. 20, no. 10, pp. 2175-2183, 2000.

[15] C. E. Murdoch, M. Zhang, A. C. Cave, and A. M. Shah, "NADPH oxidase-dependent redox signalling in cardiac hypertrophy, remodelling and failure," Cardiovascular Research, vol. 71, no. 2, pp. 208-215, 2006.

[16] J. M. Downey, T. Miura, L. J. Eddy et al., "Xanthine oxidase is not a source of free radicals in the ischemic rabbit heart," Journal of Molecular and Cellular Cardiology, vol. 19, no. 11, pp. 1053-1060, 1987.

[17] L. J. Eddy, J. R. Stewart, H. P. Jones, T. D. Engerson, J. M. McCord, and J. M. Downey, "Free radical-producing enzyme, xanthine oxidase, is undetectable in human hearts," The American Journal of Physiology-Heart and Circulatory Physiology, vol. 253, no. 3, pp. H709-H711, 1987.

[18] K. M. Minhas, R. M. Saraiva, K. H. Schuleri et al., "Xanthine oxidoreductase inhibition causes reverse remodeling in rats with dilated cardiomyopathy," Circulation Research, vol. 98, no. 2, pp. 271-279, 2006.

[19] T. Ide, H. Tsutsui, S. Kinugawa et al., "Mitochondrial electron transport complex I is a potential source of oxygen free radicals in the failing myocardium," Circulation Research, vol. 85, no. 4, pp. 357-363, 1999.

[20] S. Umar and A. Van Der Laarse, "Nitric oxide and nitric oxide synthase isoforms in the normal, hypertrophic, and failing heart," Molecular and Cellular Biochemistry, vol. 333, no. 1-2, pp. 191-201, 2010.

[21] E. Takimoto, H. C. Champion, M. Li et al., "Oxidant stress from nitric oxide synthase-3 uncoupling stimulates cardiac pathologic remodeling from chronic pressure load," Journal of Clinical Investigation, vol. 115, no. 5, pp. 1221-1231, 2005.

[22] W. F. Saavedra, N. Paolocci, M. E. St. John et al., "Imbalance between xanthine oxidase and nitric oxide synthase signaling pathways underlies mechanoenergetic uncoupling in the failing heart," Circulation Research, vol. 90, no. 3, pp. 297-304, 2002.

[23] Y. Yue, Q. Qin, M. V. Cohen, J. M. Downey, and S. D. Critz, "The relative order of mKATP channels, free radicals and p38 MAPK in preconditioning's protective pathway in rat heart," Cardiovascular Research, vol. 55, no. 3, pp. 681-689, 2002.

[24] C. N. White, C.-C. Liu, A. Garcia et al., "Activation of cAMPdependent signaling induces oxidative modification of the cardiac $\mathrm{Na}^{+}-\mathrm{K}^{+}$pump and inhibits its activity," Journal of Biological Chemistry, vol. 285, no. 18, pp. 13712-13720, 2010.

[25] Q.-M. Zhao, T.-T. Feng, X. Zhao et al., "Imaging of atherosclerotic aorta of rabbit model by detection of plaque inflammation with fluorine-18 fluorodeoxyglucose positron emission tomography/computed tomography," Chinese Medical Journal, vol. 124, no. 6, pp. 911-917, 2011.
[26] A. Filer, D. Nicholls, R. Corston, P. Carey, and P. Bacon, "Takayasu arteritis and atherosclerosis: illustrating the consequences of endothelial damage," Journal of Rheumatology, vol. 28, no. 12, pp. 2752-2753, 2001.

[27] V. Nayar, A. Santarsieri, and M. Belham, "Interrupted aorta in mosaic Turner syndrome," Cardiology Journal, vol. 18, no. 5, pp. 568-569, 2011.

[28] M. K. Halushka, "Single gene disorders of the aortic wall," Cardiovascular Pathology, vol. 21, no. 4, pp. 240-244, 2012.

[29] L. Gao, K. L. Siu, K. Chalupsky et al., "Role of uncoupled endothelial nitric oxide synthase in abdominal aortic aneurysm formation: treatment with folic acid," Hypertension, vol. 59, no. 1, pp. 158-166, 2012.

[30] K. H. Mortensen, B. E. Hjerrild, K. Stochholm et al., "Dilation of the ascending aorta in Turner syndrome-a prospective cardiovascular magnetic resonance study," Journal of Cardiovascular Magnetic Resonance, vol. 13, no. 1, article 24, 2011.

[31] S. Doganay, E. Kocakoc, and Y. Sen, "Aortic aneurysm in a girl with Takayasu's arteritis," New Zealand Medical Journal, vol. 123, no. 1326, pp. 124-125, 2010.

[32] T. Hirase and K. Node, "Endothelial dysfunction as a cellular mechanism for vascular failure," The American Journal of Physiology-Heart and Circulatory Physiology, vol. 302, no. 3, pp. H499-H505, 2012.

[33] N. Espinola-Zavaleta, M. E. Soto-López, E. Carreón-Torres et al., "Altered flow-mediated vasodilatation, low paraoxonase-1 activity, and abnormal high-density lipoprotein subclass distribution in Takayasu's arteritis," Circulation Journal, vol. 73, no. 4, pp. 760-766, 2009.

[34] J. E. Ostberg, A. E. Donald, J. P. J. Halcox, C. Storry, C. McCarthy, and G. S. Conway, "Vasculopathy in Turner syndrome: arterial dilatation and intimal thickening without endothelial dysfunction," Journal of Clinical Endocrinology and Metabolism, vol. 90, no. 9, pp. 5161-5166, 2005.

[35] H. T. Syyong, A. W. Y. Chung, H. H. C. Yang, and C. Van Breemen, "Dysfunction of endothelial and smooth muscle cells in small arteries of a mouse model of Marfan syndrome," British Journal of Pharmacology, vol. 158, no. 6, pp. 1597-1608, 2009.

[36] G. Moinuddin, M. N. Inamdar, K. S. Kulkarni, and C. Kulkarni, "Modulation of hemodynamics, endogenous antioxidant enzymes, and pathophysiological changes by angiotensinconverting enzyme inhibitors in pressure-overload rats," Hellenic Journal of Cardiology, vol. 52, no. 3, pp. 216-226, 2011.

[37] N. Mahajan, V. Dhawan, S. Malik, and S. Jain, "Implication of oxidative stress and its correlation with activity of matrix metalloproteinases in patients with Takayasu's arteritis disease," International Journal of Cardiology, vol. 145, no. 2, pp. 286-288, 2010.

[38] E. F. Davidenkova, V. V. Grigor'eva, M. G. Shafran, D. K. Verlinskaia, and M. V. Prozorova, "Lipid peroxidation and the myeloperoxidase activity of neutrophilic leukocytes in shereshevskyǐ-Turner syndrome," Byulleten Eksperimentalnoi Biologii i Meditsiny, vol. 94, no. 8, pp. 72-73, 1982.

[39] H. Bentall and A. De Bono, "A technique for complete replacement of the ascending aorta," Thorax, vol. 23, no. 4, pp. 338-339, 1968.

[40] L. Faivre, G. Collod-Beroud, L. Adès et al., "The new Ghent criteria for Marfan syndrome: what do they change?" Clinical Genetics, vol. 81, no. 5, pp. 433-442, 2012.

[41] W. P. Arend, B. A. Michel, D. A. Bloch et al., "The American College of Rheumatology 1990 criteria for the classification of 
Takayasu arteritis," Arthritis and Rheumatism, vol. 33, no. 8, pp. 1129-1134, 1990.

[42] A. Kleczkowska, E. Dmoch, E. Kubien, J. P. Fryns, and H. Van den Berghe, "Cytogenetic findings in a consecutive series of 478 patients with Turner syndrome. The Leuven experience 19651989," Genetic Counseling, vol. 1, no. 3-4, pp. 227-233, 1990.

[43] World Medical Association, "Declaration of Helsinki. Ethical principles for medical research involving human subjects," Nursing Ethics, vol. 9, no. 1, pp. 105-109, 2002.

[44] O. H. Lowry, N. J. Rosebrough, A. L. Farr, and R. J. Randall, "Protein measurement with the Folin phenol reagent," The Journal of Biological Chemistry, vol. 193, no. 1, pp. 265-275, 1951.

[45] I. Pérez-Torres, P. Roque, M. El Hafidi, E. Diaz-Diaz, and G. Baños, "Association of renal damage and oxidative stress in a rat model of metabolic syndrome. Influence of gender," Free Radical Research, vol. 43, no. 8, pp. 761-771, 2009.

[46] L. Flohe and F. Otting, "Oxygen radicals in biological systems," Methods Enzymology, vol. 105, pp. 501-600, 1984.

[47] E. M. Gregory and I. Fridovich, "Visualization of catalase on acrylamide gels," Analytical Biochemistry, vol. 58, no. 1, pp. 5762, 1974.

[48] E. Beutler, "The relationship of red cell enzymes to red cell lifespan," Blood Cells, vol. 14, no. 1, pp. 69-75, 1988.

[49] L. Flohé and W. A. Günzler, "Assays of glutathione peroxidase," Methods Enzymology, vol. 105, no. 1, pp. 114-121, 1984.

[50] J. Belik, R. P. Jankov, J. Pan, M. Yi, C. R. Pace-Asciak, and A. K. Tanswell, "Effect of 8-isoprostaglandin F2 $\alpha$ on the newborn rat pulmonary arterial muscle and endothelium," Journal of Applied Physiology, vol. 95, no. 5, pp. 1979-1985, 2003.

[51] V. Dhawan, N. Mahajan, and S. Jain, "Role of C-C chemokines in Takayasu's arteritis disease," International Journal of Cardiology, vol. 112, no. 1, pp. 105-111, 2006.

[52] S. J. Miller, W. C. Watson, K. A. Kerr et al., "Development of progressive aortic vasculopathy in a rat model of aging," The American Journal of Physiology-Heart and Circulatory Physiology, vol. 293, no. 5, pp. H2634-H2643, 2007.

[53] R. Rezzani, F. Bonomini, S. Tengattini, A. Fabiano, and R. Bianchi, "Atherosclerosis and oxidative stress," Histology and Histopathology, vol. 23, no. 3, pp. 381-390, 2008.

[54] S. K. Roy Chowdhury, G. V. Sangle, X. Xie, G. L. Stelmack, A. J. Halayko, and G. X. Shen, "Effects of extensively oxidized low-density lipoprotein on mitochondrial function and reactive oxygen species in porcine aortic endothelial cells," The American Journal of Physiology -Endocrinology and Metabolism, vol. 298, no. 1, pp. E89-E98, 2010.

[55] F. M. Faraci and S. P. Didion, "Vascular protection: superoxide dismutase isoforms in the vessel wall," Arteriosclerosis, Thrombosis, and Vascular Biology, vol. 24, no. 8, pp. 1367-1373, 2004.

[56] S. Buldanlioglu, S. Turkmen, H. B. Ayabakan et al., "Nitric oxide, lipid peroxidation and antioxidant defence system in patients with active or inactive Behçet's disease," British Journal of Dermatology, vol. 153, no. 3, pp. 526-530, 2005.

[57] P. H. Chan, M. Kawase, K. Murakami et al., "Overexpression of SOD1 in transgenic rats protects vulnerable neurons against ischemic damage after global cerebral ischemia and reperfusion," Journal of Neuroscience, vol. 18, no. 20, pp. 8292-8299, 1998.

[58] E. D. van Deel, Z. Lu, X. Xu et al., "Extracellular superoxide dismutase protects the heart against oxidative stress and hypertrophy after myocardial infarction," Free Radical Biology and Medicine, vol. 44, no. 7, pp. 1305-1313, 2008.
[59] V. Lubrano, P. Di Cecco, and G. C. Zucchelli, "Role of superoxide dismutase in vascular inflammation and in coronary artery disease," Clinical and Experimental Medicine, vol. 6, no. 2, pp. 84-88, 2006.

[60] F. Mármol, J. Sánchez, D. López et al., "Loss of adaptation to oxidative stress as a mechanism for aortic damage in aging rats," Journal of Physiology and Biochemistry, vol. 63, no. 3, pp. 239247, 2007.

[61] Y. Wei, A. T. Whaley-Connell, K. Chen et al., "NADPH oxidase contributes to vascular inflammation, insulin resistance, and remodeling in the transgenic (mRen2) rat," Hypertension, vol. 50, no. 2, pp. 384-391, 2007.

[62] S. P. Didion, M. J. Ryan, L. A. Didion, P. E. Fegan, C. D. Sigmund, and F. M. Faraci, "Increased superoxide and vascular dysfunction in CuZnSOD-deficient mice," Circulation Research, vol. 91, no. 10, pp. 938-944, 2002.

[63] T. Kondo, A. G. Reaume, T.-T. Huang et al., "Reduction of CuZn-superoxide dismutase activity exacerbates neuronal cell injury and edema formation after transient focal cerebral ischemia," Journal of Neuroscience, vol. 17, no. 11, pp. 4180-4189, 1997.

[64] J. Xu, S. Wang, M. Zhang, Q. Wang, S. Asfa, and M.-H. Zou, "Tyrosine nitration of PA700 links proteasome activation to endothelial dysfunction in mouse models with cardiovascular risk factors," PLoS ONE, vol. 7, no. 1, Article ID e29649, 2012.

[65] K. Suzuki, H. Tatsumi, S. Satoh et al., "Manganese-superoxide dismutase in endothelial cells: localization and mechanism of induction," The American Journal of Physiology-Heart and Circulatory Physiology, vol. 265, no. 4, pp. H1173-H1178, 1993.

[66] L. A. Macmillan-Crow and D. L. Cruthirds, "Invited review: manganese superoxide dismutase in disease," Free Radical Research, vol. 34, no. 4, pp. 325-336, 2001.

[67] G. A.Visner, S. E. Chesrown, J. Monnier, U. S. Ryan, and H. S. Nick, "Regulation of manganese superoxide dismutase: IL1 and TNF induction in pulmonary artery and microvascular endothelial cells," Biochemical and Biophysical Research Communications, vol. 188, no. 1, pp. 453-462, 1992.

[68] B. H. Youseff, E. D. Holbrook, K. A. Smolnycki, and C. A. Rappleye, "Extracellular superoxide dismutase protects Histoplasma yeast cells from host-derived oxidative stress," PLoS Pathogens, vol. 8, no. 5, Article ID e1002713, 2012.

[69] S. Ülker, D. McMaster, P. P. McKeown, and U. Bayraktutan, "Impaired activities of antioxidant enzymes elicit endothelial dysfunction in spontaneous hypertensive rats despite enhanced vascular nitric oxide generation," Cardiovascular Research, vol. 59, no. 2, pp. 488-500, 2003.

[70] S. W. Ballinger, C. Patterson, C. A. Knight-Lozano et al., "Mitochondrial integrity and function in atherogenesis," Circulation, vol. 106, no. 5, pp. 544-549, 2002.

[71] M. Zanetti, J. Sato, Z. S. Katusic, and T. O'Brien, "Gene transfer of superoxide dismutase isoforms reverses endothelial dysfunction in diabetic rabbit aorta," The American Journal of Physiology-Heart and Circulatory Physiology, vol. 280, no. 6, pp. H2516-H2523, 2001.

[72] T. Nishikawa, D. Edelstein, X. L. Du et al., "Normalizing mitochondrial superoxide production blocks three pathways of hyperglycaemic damage," Nature, vol. 404, no. 6779, pp. 787790, 2000.

[73] G. Rizki, C. L. Picard, C. Pereyra, and S. S. Lee, "Host cell factor 1 inhibits SKN-1 to modulate oxidative stress responses in Caenorhabditis elegans," Aging Cell, vol. 11, no. 4, pp. 717-721, 2012. 
[74] J. Serratrice, A. Benyamine, V. Vidal et al., "Simultaneous occurrence of diffuse Takayasu's arteritis and severe disseminated tuberculosis," Revue de Medecine Interne, vol. 29, no. 6, pp. 520523, 2008.

[75] G. S. Kerr, C. W. Hallahan, J. Giordano et al., "Takayasu arteritis," Annals of Internal Medicine, vol. 120, no. 11, pp. 919-929, 1994.

[76] A. G. Rose and C. C. Sinclair-Smith, "Takayasu's arteritis: a study of 16 autopsy cases," Archives of Pathology and Laboratory Medicine, vol. 104, no. 5, pp. 231-237, 1980.

[77] A. Duzova, Ö. Türkmen, A. Çinar, S. Çekirge, U. Saatci, and S. Ozen, "Takayasu's arteritis and tuberculosis: a case report," Clinical Rheumatology, vol. 19, no. 6, pp. 486-489, 2000.

[78] S. Golubović, I. Stanković, L. Ristić, V. Cosić, I. Dordević, and M. Radović, "Antioxidant enzymes and lipid peroxidation products in patients with pulmonary tuberculosis," Medicinski Pregled, vol. 63, no. 7-8, pp. 450-453, 2010.

[79] J.-N. Wang, N. Shi, and S.-Y. Chen, "Manganese superoxide dismutase inhibits neointima formation through attenuation of migration and proliferation of vascular smooth muscle cells," Free Radical Biology and Medicine, vol. 52, no. 1, pp. 173-181, 2012.

[80] G. S. Dhaunsi, M. H. M. Yousif, S. Akhtar, M. C. Chappell, D. I. Diz, and I. F. Benter, "Angiotensin-(1-7) prevents diabetesinduced attenuation in PPAR- $\gamma$ and catalase activities," European Journal of Pharmacology, vol. 638, no. 1-3, pp. 108-114, 2010.

[81] X. F. Zhou, J. Cui, A. L. Destefano et al., "Polymorphisms in the promoter region of catalase gene and essential hypertension," Disease Markers, vol. 21, no. 1, pp. 3-7, 2005.

[82] R. Polimanti, S. Piacentini, N. Lazzarin, M. A. Re, D. Manfellotto, and M. Fuciarelli, "Glutathione S-transferase variants as risk factor for essential hypertension in Italian patients," Molecular and Cellular Biochemistry, vol. 357, no. 1-2, pp. 227233, 2011.

[83] J. Rybka, D. Kupczyk, K. Kędziora-Kornatowska et al., "Glutathione-related antioxidant defense system in elderly patients treated for hypertension," Cardiovascular Toxicology, vol. 11, no. 1, pp. 1-9, 2011.

[84] B. L. Gupta, A. Preet, and N. Z. Baquer, "Protective effects of sodium orthovanadate in diabetic reticulocytes and ageing red blood cells of Wistar rats," Journal of Biosciences, vol. 29, no. 1, pp. 73-79, 2004.

[85] H. Nandeesha, V. Sathiyapriya, Z. Bobby, P. Pavithran, A. Agrawal, and N. Selvaraj, "Altered oxidant-antioxidant status in non-obese men with moderate essential hypertension," Indian Journal of Medical Sciences, vol. 61, no. 6, pp. 326-331, 2007.

[86] Y. Chen, M. Zhou, and H. Kong, "Lipoperoxidative damage in experimental rabbits with atherosclerosis," Chinese Medical Journal, vol. 106, no. 2, pp. 110-114, 1993.

[87] V. Z. Lankin, "Lipid peroxides and atherosclerosis. Hypothesis: the role of cholesterol and free radical lipid peroxidation in alteration of the cell membrane properties in hypercholesterolemia and atherosclerosis," Kardiologiya, vol. 20, no. 8, pp. 42-48, 1980.

[88] A. Ahmad, U. Singhal, M. M. Hossain, N. Islam, and I. Rizvi, "The role of the endogenous antioxidant enzymes and malondialdehyde in essential hypertension," Journal of Clinical and Diagnostic Research, vol. 7, no. 6, pp. 987-990, 2013.

[89] H. H. C. Yang, C. van Breemen, and A. W. Y. Chung, "Vasomotor dysfunction in the thoracic aorta of Marfan syndrome is associated with accumulation of oxidative stress," Vascular Pharmacology, vol. 52, no. 1-2, pp. 37-45, 2010.

[90] A. W. Y. Chung, K. Au Yeung, S. F. Cortes et al., "Endothelial dysfunction and compromised eNOS/Akt signaling in the thoracic aorta during the progression of Marfan syndrome," British Journal of Pharmacology, vol. 150, no. 8, pp. 1075-1083, 2007.

[91] X. Jiang, F. Yang, H. Tan et al., "Hyperhomocystinemia impairs endothelial function and eNOS activity via PKC activation," Arteriosclerosis, Thrombosis, and Vascular Biology, vol. 25, no. 12, pp. 2515-2521, 2005.

[92] S. D. Chauhan, G. Seggara, P. A. Vo, R. J. Macallister, A. J. Hobbs, and A. Ahluwalia, "Protection against lipopolysaccharideinduced endothelial dysfunction in resistance and conduit vasculature of iNOS knockout mice," The FASEB Journal, vol. 17, no. 6, pp. 773-775, 2003.

[93] W. Xiong, J. Mactaggart, R. Knispel et al., "Inhibition of reactive oxygen species attenuates aneurysm formation in a murine model," Atherosclerosis, vol. 202, no. 1, pp. 128-134, 2009.

[94] J. E. Barbato, B. S. Zuckerbraun, M. Overhaus, K. G. Raman, and E. Tzeng, "Nitric oxide modulates vascular inflammation and intimal hyperplasia in insulin resistance and the metabolic syndrome," The American Journal of Physiology-Heart and Circulatory Physiology, vol. 289, no. 1, pp. H228-H236, 2005.

[95] A. S. Levy, J. C. S. Chung, J. T. Kroetsch, and J. W. E. Rush, "Nitric oxide and coronary vascular endothelium adaptations in hypertension," Vascular Health and Risk Management, vol. 5, pp. 1075-1087, 2009.

[96] M. Y. Lee and K. K. Griendling, "Redox signaling, vascular function, and hypertension," Antioxidants and Redox Signaling, vol. 10, no. 6, pp. 1045-1059, 2008.

[97] M. Li and N. K. Fukagawa, "Age-related changes in redox signaling and VSMC function," Antioxidants and Redox Signaling, vol. 12, no. 5, pp. 641-655, 2010.

[98] A. Piechota-Polanczyk, A. Goraca, S. Demyanets et al., "Simvastatin decreases free radicals formation in the human abdominal aortic aneurysm wall via NF- $\kappa$ B," European Journal of Vascular and Endovascular Surgery, vol. 44, no. 2, pp. 133-137, 2012. 


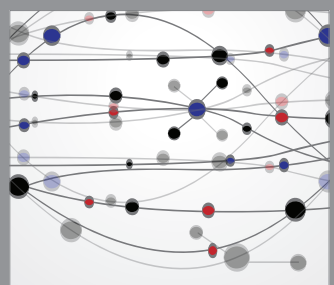

The Scientific World Journal
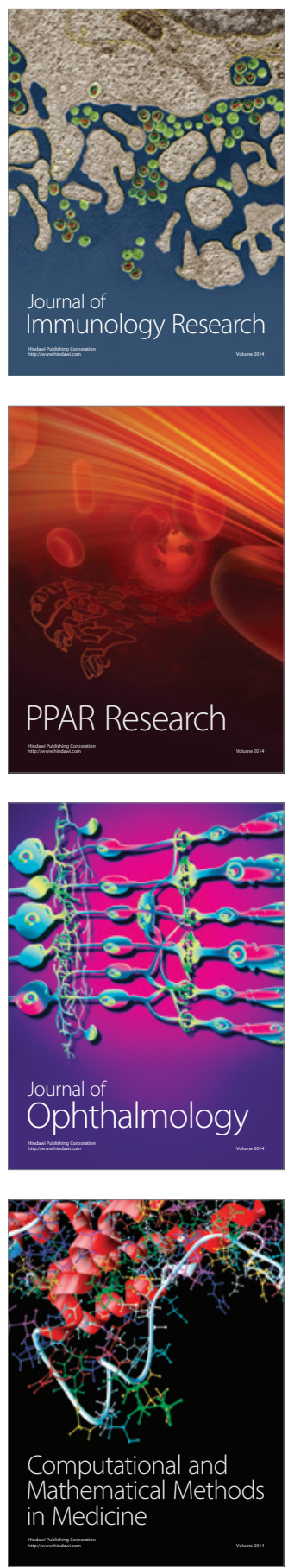

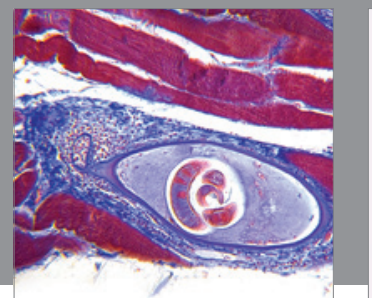

Gastroenterology

Research and Practice
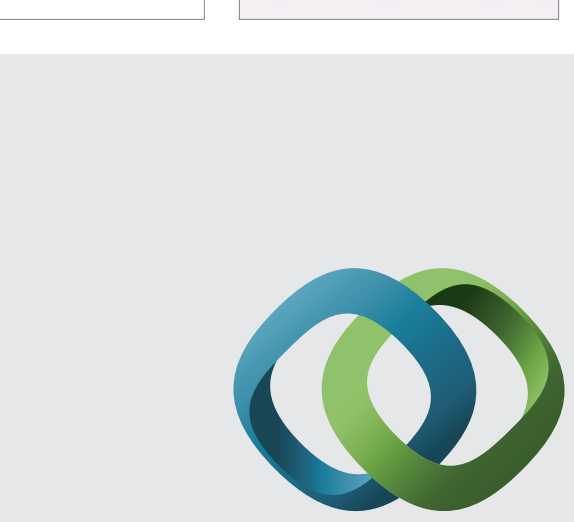

\section{Hindawi}

Submit your manuscripts at

http://www.hindawi.com
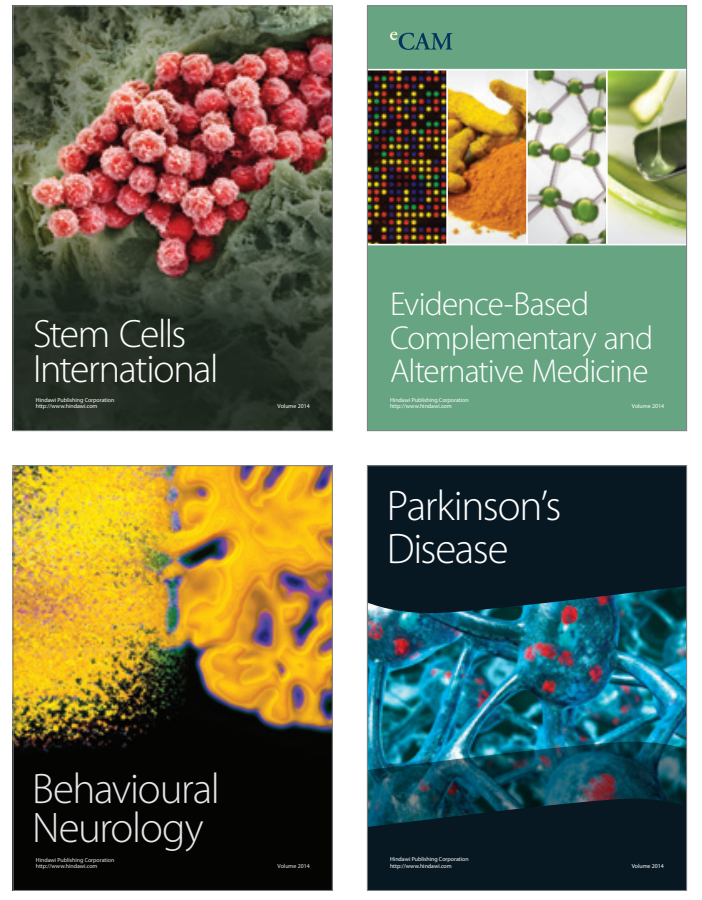
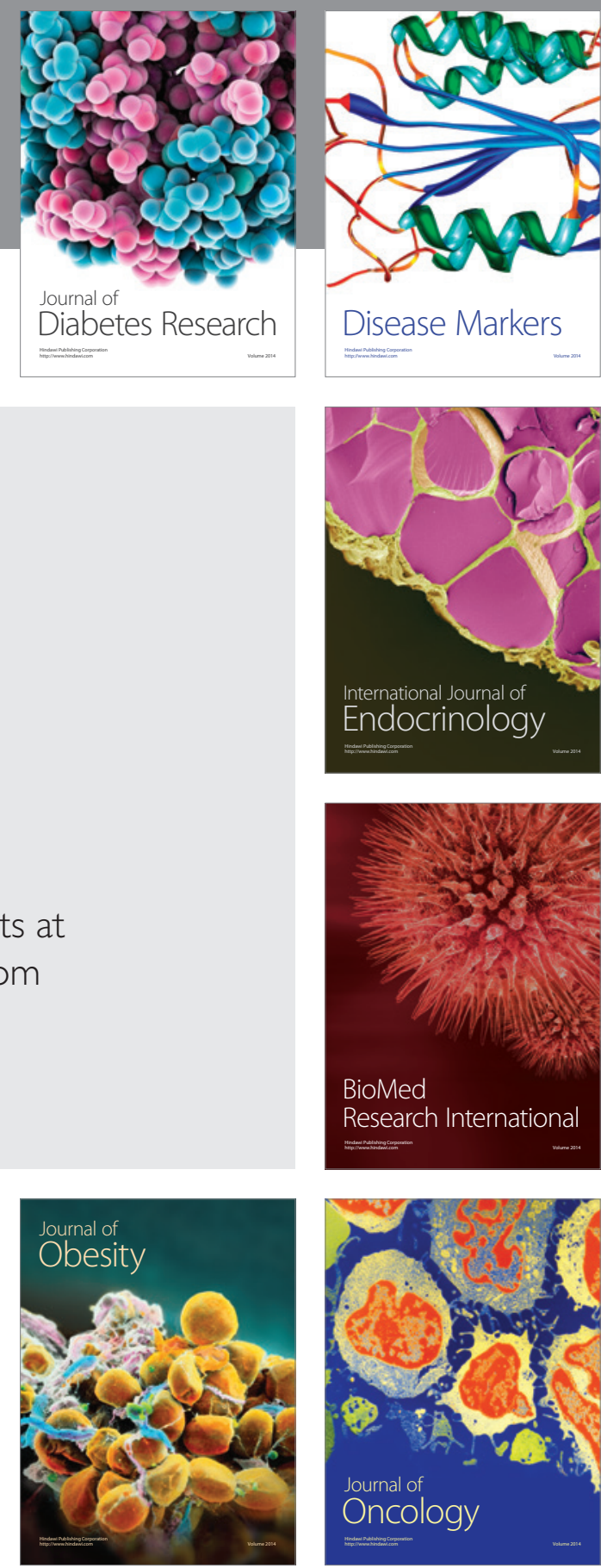

Disease Markers
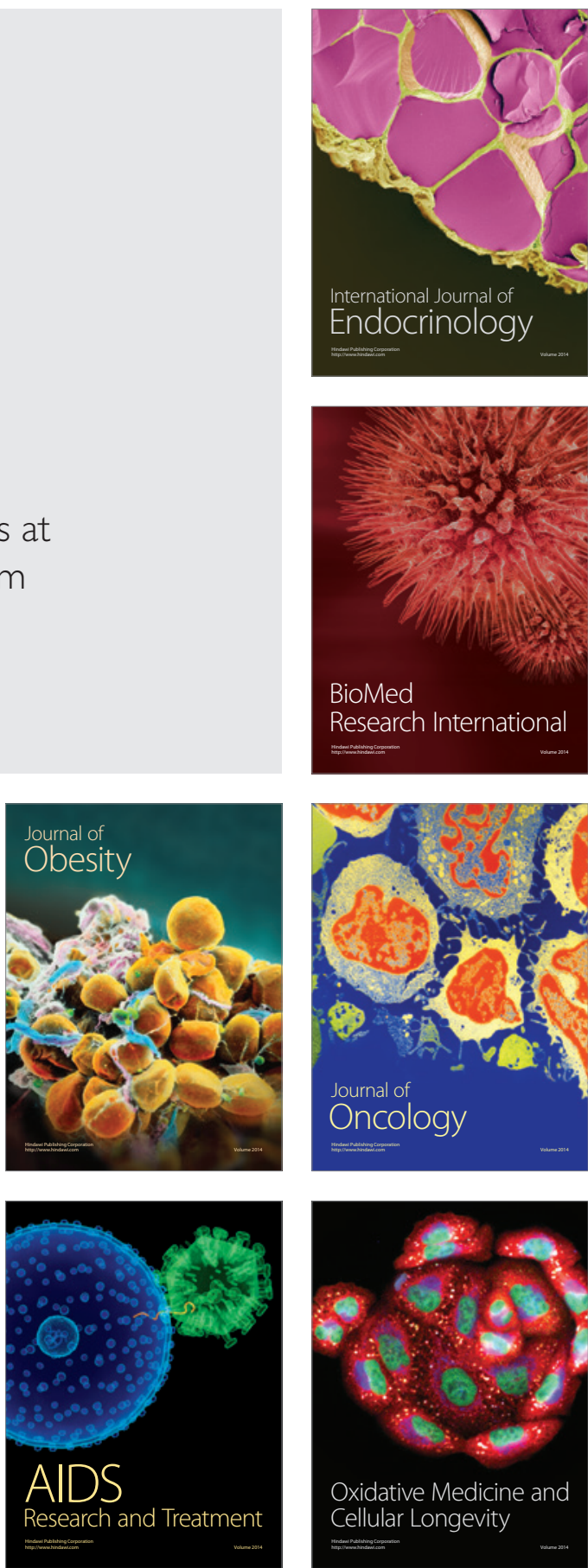